\title{
Acciones contra la estacionalidad del turismo en la Costa del Sol a finales de los 60. Fundación y reconocimiento de otro fenómeno urbano
}

JUAN GAVILANES VÉLAZ DE MEDRANO

> Universidad de Málaga, Málaga, España. jgavilanes@uma

Universidad de Valparaíso

Facultad de Arquitectura

Revista Márgenes

Espacio Arte Sociedad

Acciones contra la estacionalidad del turismo en

la Costa del Sol a finales de los 60 . Fundación y reconocimiento

de otro fenómeno urbano

Septiembre 2015 Vol. 12 № 16

Páginas 79 a 94

ISSN elec. 0719-4463

ISSN imp. 0718-4034

Recepción: Agosto 2015

Aceptación: Noviembre 2015

\section{RESUMEN}

Durante los primeros años 60 , la evolución económica de la Costa del Sol y la constatación del turismo como nueva fuente de ingresos, no encontró reflejo de estructuras convencionales de poder. Ningún edificio ni proyecto, por la propia naturaleza temporal del fenómeno, pretendía representar la llegada colonizadora de otro estatus. En esto fue determinante el factor del buen tiempo ligado a unas fechas del año. La posibilidad de una cierta vida cosmopolita apagaba sus luces durante los meses de invierno. La temporalidad suponía la constatación de que se vivía una vida a medias, en lugares a medias, con todas las comodidades propias de la modernización de esos años con las luces encendidas como en una función, para un tiempo determinado, para poco después dejar caer el telón.

Esta vida a medias sólo precisaría de unos servicios a medias o, simplemente por extensión, de una ciudad "a medias". El turismo generaba un uso excesivamente estacional del territorio, contrario al mantenimiento y a la inversión pública duradera.

Interesará por tanto descubrir si el Estado participó en la construcción de alguna arquitectura institucional que certificase el proceso iniciado en 1959 a raíz del Primer Plan de Estabilización de los gobiernos tecnócratas franquistas.

Por otro lado en un territorio dejado a la inversión privada, fácilmente empezarían a surgir demandas al Estado de amparo legal y aumento de infraestructuras. Con ello se protegerían las inversiones y se garantizaría la amortización y el futuro de las mismas. Parte de la estrategia a este respecto buscó atajar el efecto económico negativo de la temporalidad sobre la zona. Los empresarios del sector implicados empezaron a buscar nuevas estrategias de dinamización.

La presente investigación analiza la evolución de los primeros edificios para congresos en la Costa del Sol, edificios modernos para un turismo de formación y enseñanza continuada y profesional. Edificios contra la estacionalidad y por tanto representantes del germen del nacimiento de una ciudad completa.

PALABRAS CLAVE

arquitectura, turismo, estacionalidad, colonización, ciudad

Actions against the seasonality of tourism in the Costa del Sol at the end of the 60s. Foundation and recognition of other urban phenomenon ABSTRACT

This research analyzes the evolution of the first buildings for conferences and conventions on the Costa del Sol. Modern buildings for training and continuing education. Buildings against seasonality, and so, buildings for the birth of an entire city.

During the early 60's, the Costa del Sol had a strong economic development. There tourism was confirmed as a new source of income. However it found no reflection of conventional power structures. No building or project intended to represent a new colonization. Good weather factor was decisive linked to certain times of the year. The possibility of a cosmopolitan life turned off their lights for the winter. By temporality we realized that we lived a half-life, with all the comforts of modernization of those years. All the lights were lit like a theater performance for shortly after the curtain falls. 
This half-life could only belong to a half-city. Tourism generated an excessively seasonal land use. And it goes against the maintenance of public investment and durability.

We are interested to find out whether the State participated in the construction of some institutional architecture. We will search some object to certify the process initiated in 1959 following the Primer Plan de Estabilización by the first Franco's technocrat government.

Besides this was an area left to private investment. Soon the private investors requested legal protection and increased infrastructure. Its aim was to demand that the first investments were protected. Their strategy tried to cut the negative economic effect of temporality on the area. The companies involved in the tourism sector began to look for new strategies of revitalization.

KEYWORDS

architecture, tourism, seasonality, colonization, city

\section{INTRODUCCIÓN. FUNDACIÓN Y RECONOCIMIENTO DE OTRO FENÓMENO URBANO}

Aunque en principio pudiese parecer exclusivamente anecdótico el detonante del cambio económico y estructural iniciado en la España de mediados del siglo XX, fue una consecuencia directa del pacto con los Estados Unidos de 1953.

Se hace difícil catalogar lo que aconteció en la Costa del Sol durante la década de los sesenta como un fenómeno urbano convencional. La condición temporal del turismo aporta a la visita una característica rotacional y estacionaria de sus habitantes. El turismo va dirigido a una sociedad parcial y artificial, los turistas no tienen arraigo con el lugar, no se sienten identificados con él y el hedonismo y disfrute de un tiempo libre vienen dados para explotar al máximo su breve estancia y romper con la rutina de la vida de la ciudad real. Sociedades efímeras o temporales semejantes se han manifestado también por otros motivos en torno por ejemplo a las residencias universitarias que sirven durante un tiempo para albergar a una sociedad joven, en formación y que al cabo de un tiempo, más prolongado que el del turismo, se van de allí.

El territorio en la Costa del Sol ocupa además una vasta extensión que precisaba de un transporte eficaz, rápido y sin necesidad de grandes infraestructuras. El automóvil se adaptaría a la primera carretera para extenderse y moverse libremente de un extremo a otro. A esto se le uniría de manera indisoluble la evolución de la aviación civil que permitía acercar a los visitantes de un lugar lejano. Por otro lado el avance de las telecomunicaciones apoyaría estos desplazamientos favoreciendo los contactos y la intercomunicación. En la época que abarca el presente estudio la tecnología predominante para comunicarse de manera instantánea con los lugares de origen sería el teléfono por cable.

Las explotaciones para el turismo surgieron primero en los mejores lugares. Se trataba de localizaciones en las que no necesariamente se asentaría como parte del crecimiento concéntrico de los pequeños núcleos rurales preexistentes. Los primeros enclaves turísticos se darían de manera espontánea en los límites entre la carretera, la costa y las laderas. A lo largo de su paisaje original se fue extendiendo el crecimiento turístico no planificado de manera efectiva. Los proyectos que se levantarían con mayor éxito serían los de pequeña y mediana escala, hoteles y edificios de apartamentos. En unos casos amparados por la ley de Centros de Interés Turístico Nacional de 1963, la cual constataría y ampararía la dificultad de establecer el control, y en otros casos como proyectos sobre solares concretos en los que la arquitectura buscaría no sólo dar respuesta a la cuestión turística sino suplir la falta de ciudad y erigirse en verdadero atractor de actividad en sus alrededores. La confluencia de todas estas cuestiones nos lleva a pensar en algo más, quizá incluso diferente e imprevisto. Cada intervención se situó como un nudo, como un nuevo cruce de caminos, como punto de encuentro entre los nuevos espacios vacantes y los visitantes. Se había iniciado una fundación coyuntural que inevitablemente daría paso a un proceso de transformaciones.

En este caso concreto se podría decir, citando las referencias a la actualidad del artículo Anyway de Solà-Morales (2009:51), que había empezado sobre la Costa del Sol un imparable proceso de colonización, aunque durante esa década de los 60 la invisibilidad del Estado pudiese hacer pensar lo contrario o al menos disimulase su inminencia. El turismo se mostraría como el germen de un nuevo intercambio económico, comercial y cultural. Su incidencia sobre territorio, paisaje y habitantes inaugura un proceso irreversible que augura una tendencia hacia una colonización imparable, contemporánea y de marcado carácter internacional.

Estamos viviendo...un proceso acelerado de internacionalización de las relaciones económicas y también físicas en partes del globo que habían permanecido incólumes a toda transformación rápida o a todo cambio de grandes dimensiones...hoy más que en cualquier otro momento de la historia económica mundial, asistimos a procesos de colonización (Solà-Morales, 2009:51).

Toda colonización en un primer momento traza límites y de alguna manera construye una visualización del poder que atenta. Los procesos contemporáneos de colonización no siempre muestran signos de violencia. Los procesos de apropiación turística enmarcan lo amable del lugar y como mucho, durante el inicio del proceso en la Costa del Sol, se situaron en el paisaje litoral como experiencias desnudas de referencias. Las primeras intervenciones que empezaron a transformar el paisaje previo no necesariamente supusieron agresión alguna. La evolución económica y la constatación del fenómeno como fuente de ingresos económicos al alza no encontró, en los primeros años, reflejo de estructuras convencionales de poder, ningún edificio ni proyecto, por la propia naturaleza temporal del fenómeno turístico pretendía representar la llegada colonizadora de otro status.

Quizá los edificios del inicio de la actividad turística nunca tuvieron la voluntad de representar esta colonización latente, máxime cuando su objetivo era meramente pragmático, para cubrir necesidades instantáneas. Quizá esa condición los hiciese desechables si no servían para los momentos y necesidades por venir. Es posible que estos proyectos y algunos otros nos hablen de una época y constaten los cambios y la evolución del territorio simplemente porque han sobrevivido. 
Jean-Paul Sartre (1945) escribiría sus ensayos sobre las ciudades americanas. Ya en esos años la visión de estas urbes y de sus territorios circundantes causaba perplejidad para un espectador ciudadano europeo acostumbrado a lo que Lynch (1960:11-15) nombraría como las claves de legibilidad. Este concepto expresa por oposición los fenómenos expansivos urbanos de los Estados Unidos y que inevitablemente han ido extendiéndose por todas las latitudes, y sirve para describir la incertidumbre perceptiva experimentada por cualquier visitante, y que se concreta en estas palabras de Sartre (1945) acerca de la ilegibilidad de la ciudad de Los Ángeles:

...Los Angeles, en particulier, ressemble à un gros ver de terre qu'on pourrait couper en vingt tronçons sans le tuer. Si vous parcourez cette énorme agglomération probablement la plus grande du monde, vous rencontrez successivement vingt villes juxtaposées, rigoureusement identiques les unes aux autres, chacune avex son quartier pauvre, ses rues commerçantes, ses boîtes de nuit, sa banlieue élégante, et vous aurez l'impression qu'un centre urbain de taille moyenne s'est reproduit à vingt exemplaires par scissiparité...Cette juxtaposition est de règle en Amérique...dans ces villes qui vont vite, qui ne sont pas construites pour vieillir et qui progressent comme les armées modernes, en encerclant des îlots de résistance qu'elles ne peuvent pas détruire, ne se manifeste pas, comme chez nous, par des monuments, mais par des résidus (Sartre, 1945) ${ }^{1}$.

No deja de ser interesante la descripción de la ciudad como un ser fragmentario pero vivo. Pudiendo establecerse comparaciones con el crecimiento paulatino que se produjo a través de entes aislados a lo largo del cordón litoral de la Costa del Sol. Por otro lado la alusión al concepto de supervivencia introduce una cuestión azarosa en la permanencia a lo largo del tiempo. Que puede ser achacable a las arquitecturas estudiadas que se cargan de información sobre la época a la vez de mostrarse como signos semiocultos que desvelan otras cuestiones y que si han sobrevivido refuerzan una componente patrimonial como imagen y testigo de una época.

Las arquitecturas e intervenciones en los lugares intermedios para el turismo parece que han soportado el paso despreocupado del tiempo en este territorio de débil colonización. Conviene preguntarse acerca de si en algún momento surgió algún otro indicio de que el proceso iniciado podría ir consolidándose o seguiría funcionando como un asentamiento de nómadas siempre efímero como sumatorio de momentos superpuestos.

El conjunto de intervenciones turísticas, hoteles, apartamentos y el crecimiento diseminado de los lugares intermedios puede atender a una categoría superior aunque provoca densidades y acontecimientos. Cuestiones relativas a la congestión, descentralización, intensidad de los desplazamientos, variaciones de densidad, etc., propias de las ciudades empezaron a aparecer en un ente urbano que tenía hipertrofiados parte de sus órganos mientras que acusaba la ausencia de otros. Si las primeras intervenciones como por ejemplo el concurso de la UIA en Elviria (1960), Marbella, potenciaba la creación de centros de atracción, la realidad negaba la evidencia. Al tratarse de una zona de promoción privada, los equipamientos turísticos comenzaron a multiplicarse mientras que otros equipamientos propios de cualquier ciudad eran inexistentes y la vivienda se ceñía a los municipios existentes para albergar a los trabajadores de este sector de servicios sobredimensionado. La intervención de la administración pública debería haberse encargado de organizar u obligar a la creación de centros cívicos, edificios escolares, comerciales en distintos grados, parques públicos, equipamientos deportivos, sanitarios. Aunque la realidad suponía que el turismo generaba un uso excesivamente estacional del territorio, contrario al mantenimiento y a la inversión pública duradera.

Por otro lado durante la época surgieron otras miradas que se verterán sobre procesos urbanos análogos que habían sido descalificados o minusvalorados. Como ejemplo de ello se encuentran los análisis de evolución primero de las formas de la arquitectura que propugnó Banham (1960), que serían clave para que con posterioridad su propia mirada sobre Los Ángeles (Banham, 1971) arrojase alguna luz sobre estos fenómenos contrarios a la lógica, hasta entonces, evolución de la ciudad al albergar unos nuevos modos de generación urbana.

El turismo introducirá una línea de fuga que hará crecer el fenómeno a lo largo del territorio. Cada nuevo edificio, cada ordenación completará el mapa de eventos y de nuevos lugares para que posteriormente se llenen los vacíos. Este crecimiento ajerárquico responderá a múltiples entradas donde el Estado no alcanzaría fácilmente el control y mucho menos el establecimiento de una unidad diferenciada y representativa. El modelo iniciado no cesaría de constituirse y desaparecer, en un proceso que no pararía de extenderse, interrumpirse y comenzar de nuevo (Deleuze \& Guattari, 1977:20, 43, 47).

La yuxtaposición de objetos en un paisaje que perdura mantiene unas claves de vitalidad que contradice su falta de planificación. Durante la década de los 60 , de manera no programada se sentaron las bases de un fenómeno dinámico que albergaría las bases de una fundación urbana.

...podemos proponer la sustitución de la representación por la presentación de las cosas... Así, la presentación de las cosas es algo totalmente distinto. Se contenta con dejar ser lo que es y se esfuerza por resaltar la riqueza, el dinamismo y la vitalidad de este "mundo de aquí.

...La presentación subraya que nunca podemos vaciar totalmente un fenómeno, es decir, algo empírico, empíricamente vivido, con una simple crítica racional (Maffesoli, 1996:24-25).

Es por ello que las arquitecturas objeto del presente estudio, hasta el momento no mostraban ninguna intención de representación. Eran meras propuestas para explotaciones comerciales de calidad en las que como mucho la contemplación de la imagen de modernidad y progreso que transmitían y de los modos de vida que inauguraban hacían evidente el desempeño de un papel que no debería tratar de desvelar ninguna realidad unívoca.

La paradoja se cierne sobre este territorio. El análisis de los primeros edificios representativos que surgieron manifiesta por su propia razón de ser la potencia de todo lo demás, como intento desesperado de afianzar otra dinámica más institucional a lo que estaba ocurriendo de hecho, apoyado además por la circunstancia de haber germinado como iniciativa de los promotores que operaban en la costa y no del Estado franquista.

...la ciudad del futuro estará a la vez en todas partes y en ninguna... una ciudad tan diferente a la ciudad anti- 
gua o de cualquier ciudad actual que probablemente no logremos reconocer su llegada como ciudad... (Frampton, 1980:192).

\section{CAMBIO DE ESCALA EN LA LADERA: CENTRO DE CONVENCIONES Y CONGRESOS DE TORREMOLINOS (1965)}

A lo largo de la década de los 60 el desarrollo turístico de la Costa del Sol empezó a manifestar una consecuencia propia del turismo estival. Aunque el clima lo permitiese, la concentración de vacaciones en los meses del verano dejaba vacíos los hoteles y apartamentos durante el resto del año. Las consecuencias de desolación se extendían a los trabajadores implicados y a unos establecimientos que reflejaban el vacío poblacional y de actividad que se extendía por la zona durante el tiempo no vacacional.

Evidentemente los efectos de esta estacionalidad en seguida tuvieron un fuerte carácter económico. De modo que los empresarios del sector implicados por sus inversiones empezaron a buscar nuevas estrategias de dinamización.

Algo que ya se había probado en otros países, fundamentalmente en los EE. UU., con cierto éxito fue el turismo de congresos. Durante los meses de temporada baja la infraestructura hotelera y de desplazamientos podía ser aprovechada para la realización de congresos científicos y profesionales. De tal manera que un público acomodado y cualificado fuese acogido en un lugar con un valor añadido al interés de formación profesional continua.

Uno de los estudios que se realizaron en la época sobre esta zona, el informe denominado "La Costa del Sol y sus problemas de 1964", fue dirigido por el arquitecto Eduardo Caballero y promovido por la Oficina de Coordinación y Desarrollo en el Gobierno Civil de Málaga. En el ámbito local tuvo bastante repercusión por lo riguroso y próximo a la realidad de su análisis de la zona. Una de las primeras consecuencias que tuvo fue el que gran parte de los empresarios y promotores implicados en la Costa del Sol contemplasen la posibilidad de agruparse para poder instar a la administración a mejorar las infraestructuras y a la vez conseguir atraer nuevas inversiones.

El 1 de septiembre de 1964 quedó constituida en el hotel Meliá Don Pepe de Marbella la Sociedad de Promotores de la Costa del Sol como Sociedad Cooperativa en cuyos estatutos constaban sus fines:

Art. $2^{\circ}$ Esta Cooperativa aspira a la propaganda, ordenación y fomento de los intereses económicos y sociales de la Zona conocida con el nombre de Costa del Sol, que comprende los términos municipales de Estepona, Marbella, Fuengirola, Mijas, Benalmádena y Málaga, a través del ejercicio de las siguientes actividades:

a. Propaganda de la Costa del Sol en España y en el ex tranjero.

b. Desarrollo de las posibilidades turísticas de la Zona...

c. Promover un consorcio con participación de la empresa privada, las Corporaciones locales de la provincia más destacadas en el aspecto turístico y la Administración Central... (Barceló, 1997:115-116).

Los operadores turísticos y algunos hoteleros comenzaron a demandar la necesidad de dar respuesta a un todavía incipiente turismo de congresos. Algunos de estos empresarios empezarían a habilitar parte de sus infraestructuras para este fin como veremos más adelante. Pero la recién creada Cooperativa de Promotores asumió el reto como suyo e instó enseguida a la administración central, concretamente al Ministerio de Información y Turismo para que acometiera la inversión necesaria. A lo cual aunque se obtuvo respuesta favorable inmediata, la realidad presupuestaria no terminó de darle forma. Por lo que la Cooperativa de Promotores decidió tomar cartas en el asunto y llevar la iniciativa y para ello buscó a los primeros arquitectos.

La primera propuesta arquitectónica que indagó en esas posibilidades fue el denominado Centro de Convenciones y Congresos de Torremolinos que apareció publicado en el número 61 de la revista Hogar y Arquitectura de noviembre-diciembre de 1965 (García de Paredes \& et al., 1965:62-64). La publicación estaba destinada a mostrar como tema central la obra de José María García de Paredes, en palabras de Carlos Flores (1965), uno de los miembros más destacados y representativos de la segunda generación de la posguerra.

La situación de esta primera propuesta fue proyectada para otro emplazamiento diferente al que se construiría finalmente. Esta versión, de 1965, fue definida a nivel de anteproyecto y no se construyó. Fue firmada por los arquitectos José María García de Paredes, Rafael de La-Hoz y Gerardo Olivares.

La naturaleza dimensional de un edificio con unos requisitos espaciales más amplios que los hoteles y apartamentos, unido a su carácter representativo hacía más delicada su ubicación, prestándose así más a una situación elevada respecto a la línea costera, algo más separada del bullicio turístico y donde las vistas panorámicas acompañasen a la visita. Bajo estas condiciones la elección del lugar adecuado se buscó en las partes altas. En cierta manera esta situación elevada para un uso comunitario y de reunión ya fue enunciada en la propuesta de Utzon para el concurso de la UIA de 1960 en Elviria, Marbella, en la que el arquitecto danés propuso un centro humanístico en la elevación en los cerros de la finca original marbellí del Coto de los Dolores.

La ubicación se convierte en una de los activadores del proyecto. En este caso, el lugar, denominado La Batería, se encuentra desplazado del núcleo urbano original de Torremolinos aunque próximo y se corresponde con un baluarte defensivo construido a finales del siglo XVIII (1770), para que protegiese con artillería, de ahí su nombre, del levante y del poniente, a los navegantes y que sirviese de cobijo a embarcaciones frente al acoso de las naves corsarias. A mediados del siglo XIX pasó a ser cuartel de carabineros y, posteriormente, propiedad privada, constituyendo hoy día un área libre denominada Parque de la Batería.

Su situación se producía en un borde agreste que afloraba como promontorio, elevándose sobre el rededor, algo que justificaría su carácter defensivo, dominador de los flancos marinos desde ese panóptico. Desde la perspectiva de la segunda mitad del siglo XX, este lugar era percibido de manera muy diferente a como lo había sido en los siglos precedentes. Algo que justificaría de manera adecuada el que se pensase ubicar este nuevo equipamiento para los congresos. Así pues, se pretendía la creación de un edificio que actuase como centro de atracción, ubicado en una colina desde el que la vista del mar estuviese garantizada para recibir de manera protocolaria a visitantes corporativos, profesionales y de todo tipo a la vez que sirviese como lugar privilegiado para observar la bahía de Málaga y su potencialidad turística. 


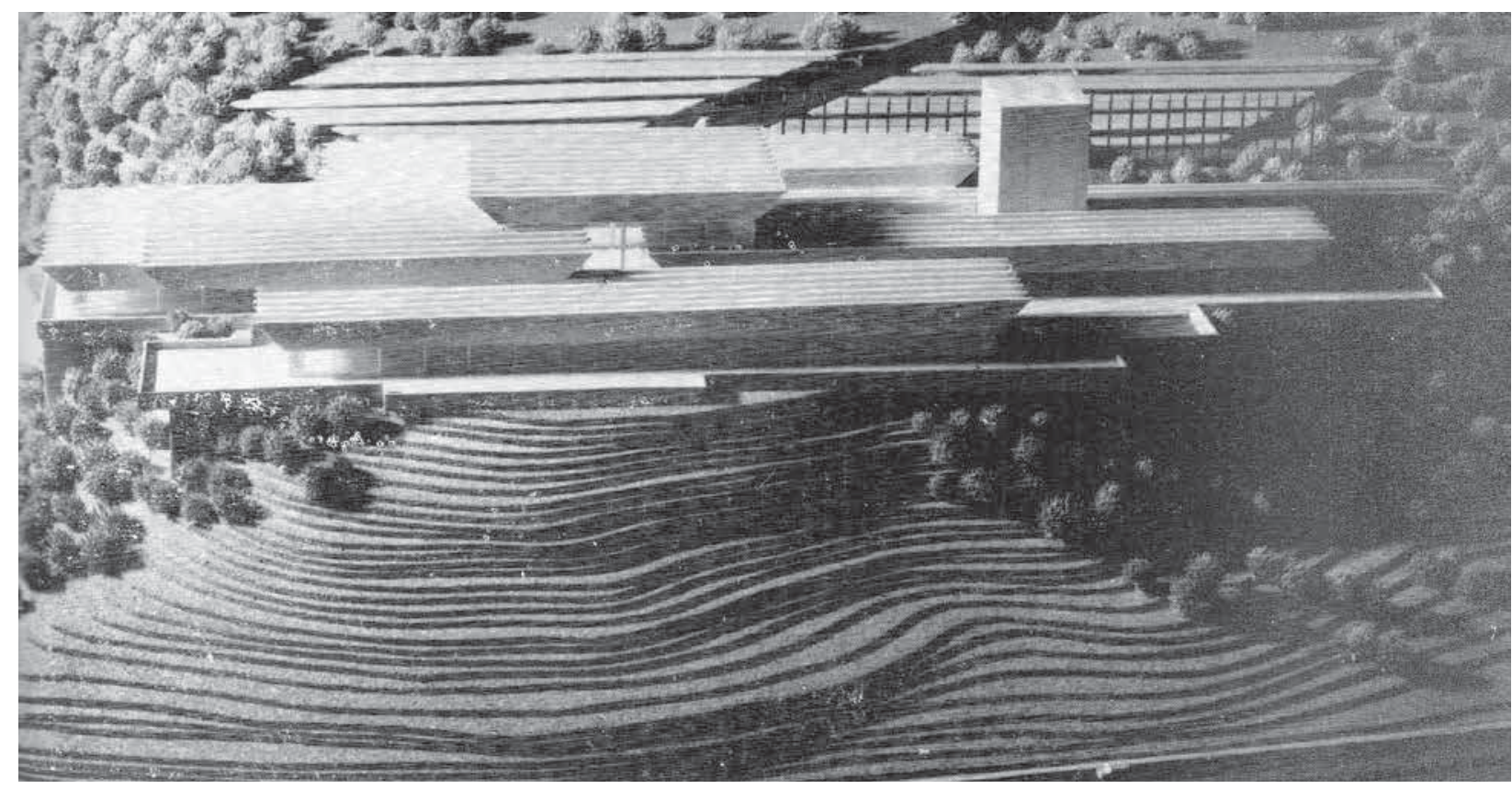

Es muy probable que el uso previo de batería militar ya hubiese dejado despejada la parte superior, de forma que el lugar funcionaba como una plataforma en alto respecto a la playa cercana, con buena parte de su borde perimetral orientado al litoral. Esto determinaba su carácter de acrópolis. El edificio debería mostrar a los visitantes el entorno bellísimo y a la vez su imagen debería ser capaz de exhibir una importante cualidad de representación de lo que empezaba a significar la Costa del Sol y de lo que allí acontecía, para poder celebrar con éxito todo tipo de reuniones y convenciones.

...Su emplazamiento es bellísimo... dominando el mar.

La belleza del emplazamiento hace aconsejable adelantar los edificios al borde mismo de la colina con un tratamiento de cornisa panorámica sobre el mar y el mediodía (García de Paredes \& et al., 1965:62-64).

Las razones del proyecto se describen con claridad en la publicación. Los edificios se adelantarán potenciando la condición de límite con el entorno. Lo que observamos en las fotos de la maqueta construye ese borde, esa plataforma de nuevo, pero será la vista dominante del mar desde esa atalaya, la que permita comprender la intervención de manera plena.

El edificio sobrepasa el perfil natural, aumentando la estricta plataforma heredada para lo que se debe construir ese nuevo borde. Para ello evita el uso de un prisma sólido y aligera su presencia mediante el uso de pantallas paralelas, cuya secuencia se repite y se adapta al perfil topográfico usando el juego de luces y sombras para mitigar la ampliación del plano superior donde se sitúan los edificios.

El conjunto supone una descomposición de cuerpos paralelos con distinta ocupación de la base, distinta anchura y distinta altura. Se distinguen patios como lugares de distribución que rompen la imagen monolítica y a su vez los diferentes volúmenes se sobreelevan unos respecto a otros según la jerarquía que marca el programa.

Se diferencian concretamente dos volúmenes. Uno que sigue la directriz horizontal de la mayoría, donde la cubierta se desliza con un borde sesgado. La intuición de su estructura permite dotar a la

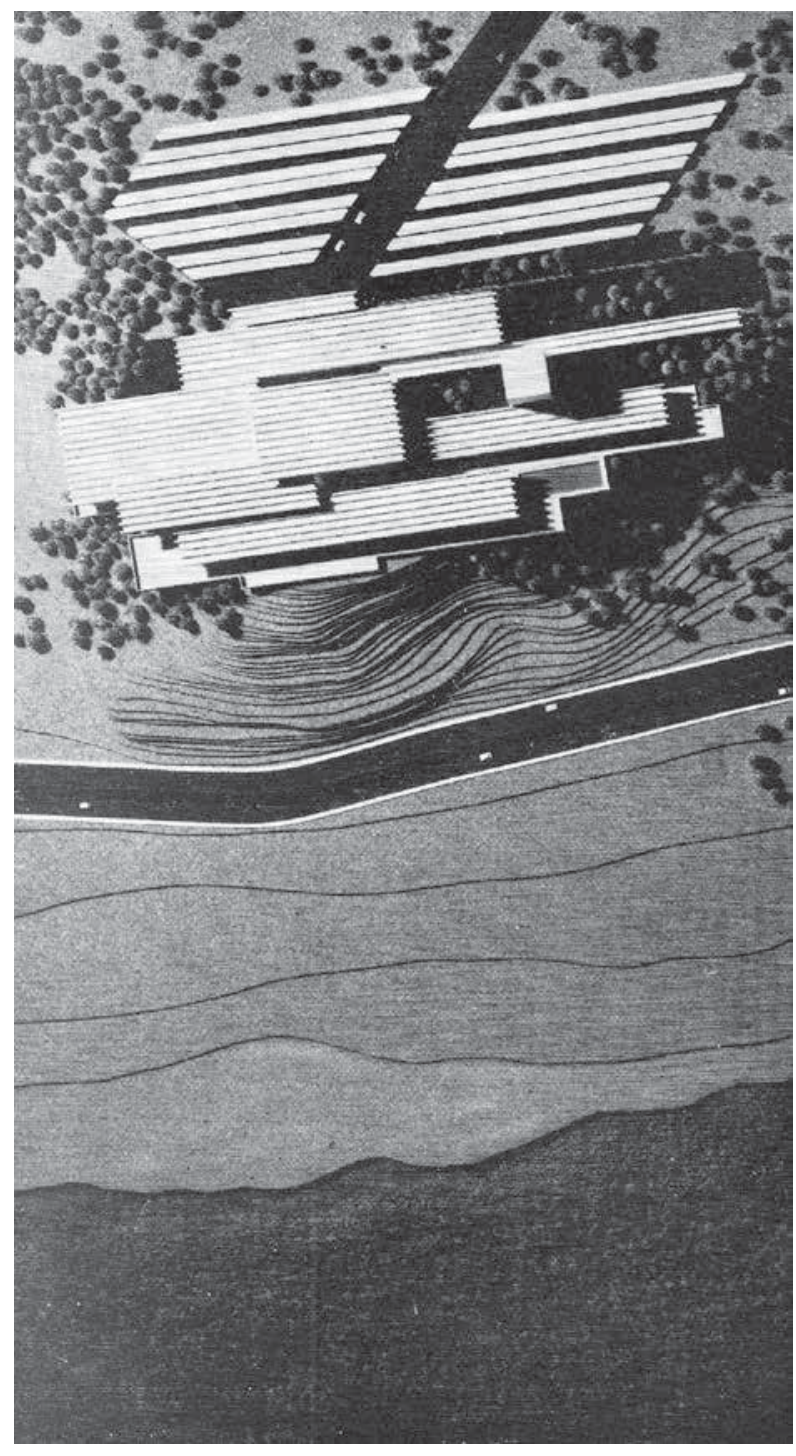

Figuras 1 y 2. Fotografías de la maqueta del Centro de Convenciones y Congresos de Torremolinos. Fuente: revista Hogar y Arquitectura, 1965.

Revista Márgenes N 16 Vol $12>$ Septiembre $2015>$ 

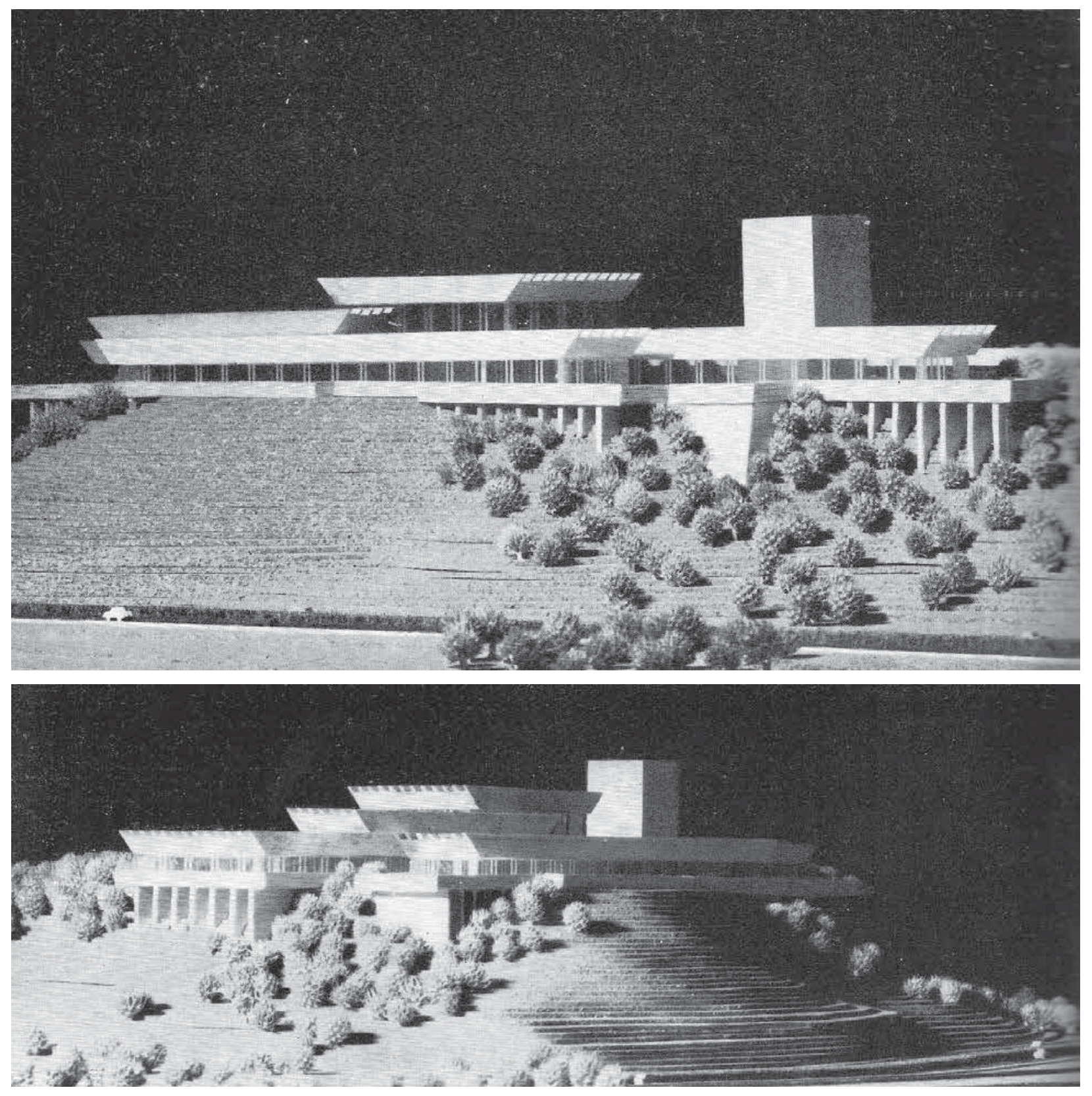

Figura 3. Vista lateral noreste del Centro de Convenciones y Congresos de Torremolinos. Fuente: revista Hogar y Arquitectura, 1965.

$>$ Figura 4. Vista lateral sureste del Centro de Convenciones y Congresos de Torremolinos. Fuente: revista Hogar y Arquitectura, 1965. cubierta de gran ligereza, reservando los espacios que cubre a las denominadas salas de asambleas. El otro cuerpo sin embargo es totalmente diferente y desequilibra la composición marcando una opción claramente vertical. Esta pieza puede recordar más a las torres vigías o más bien a una torre del homenaje que ancla la propuesta, siendo su elemento más cerrado, destinado a las oficinas. Por otro lado el proyecto redunda en su condición de borde frente al mar con el uso de un mirador replegado, como base misma del edificio y que pretende mostrarnos el recorrido exterior y perimetral del observador de la bahía. Se genera una tensión horizontal entre el paisaje circundante y las vísceras del edificio. La condición de transparencia en el borde define una actitud de reconocimiento hacia el paisaje que trasciende el acontecimiento de su interior.

Este proyecto parece dar un paso más respecto a las propuestas que sobre las crestas de la topografía presentaba el proyecto de Utzon para el concurso de Elviria en Marbella (Utzon, 1960). El Centro de Convenciones y Congresos parte de un concepto semejante. Es en la definición del edificio donde se puede apreciar una mayor evolución del referente. Lo que en el Utzon suele ser, incluso en 


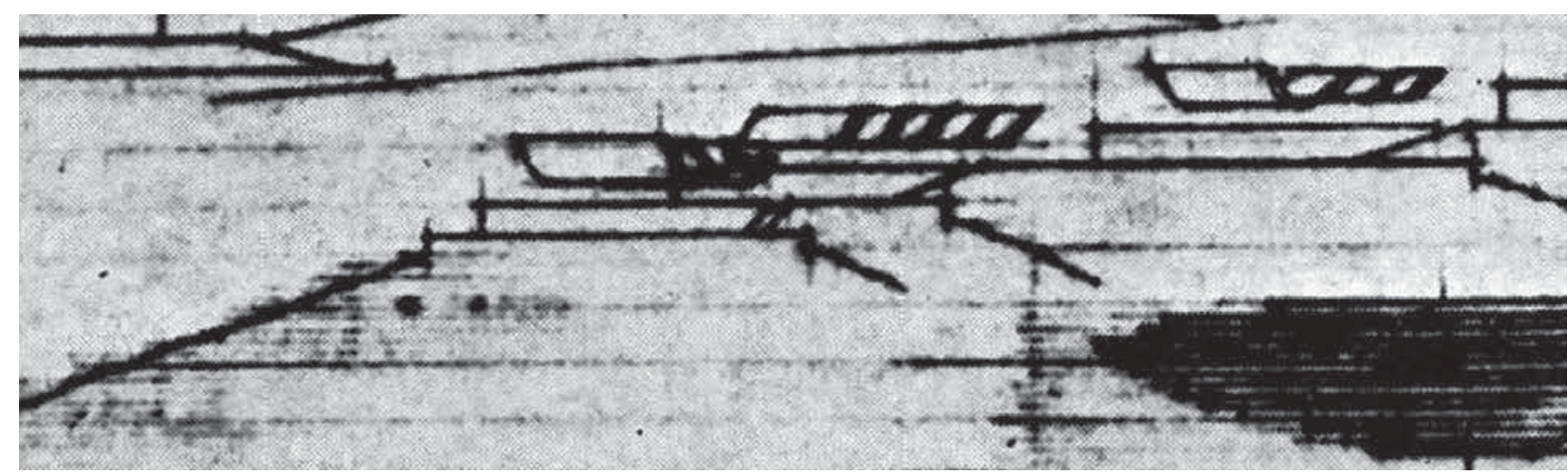

otros de sus proyectos, una sugerente indefinición de la cubierta que se asienta sobre la plataforma, en el anteproyecto del Palacio de Convenciones de Torremolinos se construye con precisión. La maqueta muestra sus elementos estructurales, su envolvente y perímetros afilados sin perder su cualidad ligera, de manera que se descubre un paso más allá de las propuestas del arquitecto danés para el mismo territorio bajo el prisma de un compromiso constructivo y estructural a favor de la belleza que permanece constante en la obra del arquitecto García de Paredes.

\section{PRIMERA INICIATIVA PRIVADA: EL HALL DE CONGRESOS DEL HOTEL ALAY (1967-1972)}

Toda vez que el Centro de Convenciones y Congresos de Torremolinos no consiguió de momento llevarse a cabo en el solar inicialmente previsto, el empresario vasco Fermín Aguirre decidió acometer por su cuenta un proyecto de explotación turística que entre sus prestaciones incluyese espacios para la celebración de congresos.

El arquitecto encargado del proyecto sería Manuel Jaén Albaitero, arquitecto de origen navarro de formación racionalista y con estudio en Madrid, con suficiente experiencia en arquitectura del turismo en la Costa del Sol. Entre sus primeros proyectos se encuentra entre otros el hotel Carihuela Palace (1960) en Torremolinos o los apartamentos Skol de Marbella (1963), ambos realizados junto a Carlos García San Miguel. Manuel Jaén compartió estudio en Madrid con Antonio Bonet Castellana, de su misma edad, cuando éste regresó a España en 1960. Con Bonet intervendría, aparte de otros proyectos en Madrid, en la Costa del Sol en varios proyectos como el de Andalucía la Nueva de Banús en Marbella (1962) o en el barrio de los Naranjos de Torremolinos (1967).

El conjunto conformaría una ordenación con un programa complejo a lo largo de una parcela rectangular entre la carretera y la playa. En ella se trataba de diversificar la oferta turística, la cual comprendería desde edificios dedicados a apartamentos hasta un hotel, con áreas libres ajardinadas y dotación de aparcamientos. La alternancia de piezas de apartamentos verticales y horizontales favorecía la apropiación de vistas, permitiendo una gradación desde usos más privados e independientes a los más públicos o con mayor número de servicios hoteleros. Las obras se fueron completando a lo largo de cinco años, hasta el año 1972 en que colaboraría también con los estudios de arquitectura recién terminados su hijo Manuel Hugo Jaén de Zulueta, en concreto en la torre que remataría finalmente el conjunto con el hotel.

El proyecto salvaba un ligero desnivel desde la carretera por lo que se previeron, aprovechado la diferencia de cotas, hasta cuatro salones de distintas dimensiones para los congresos y convenciones en el borde final aterrazado al mar.

Figura 5. Detalle de la propuesta de Utzon para el concurso de Elviria, 1960. Fuente: revista Zodiac, 1962. 

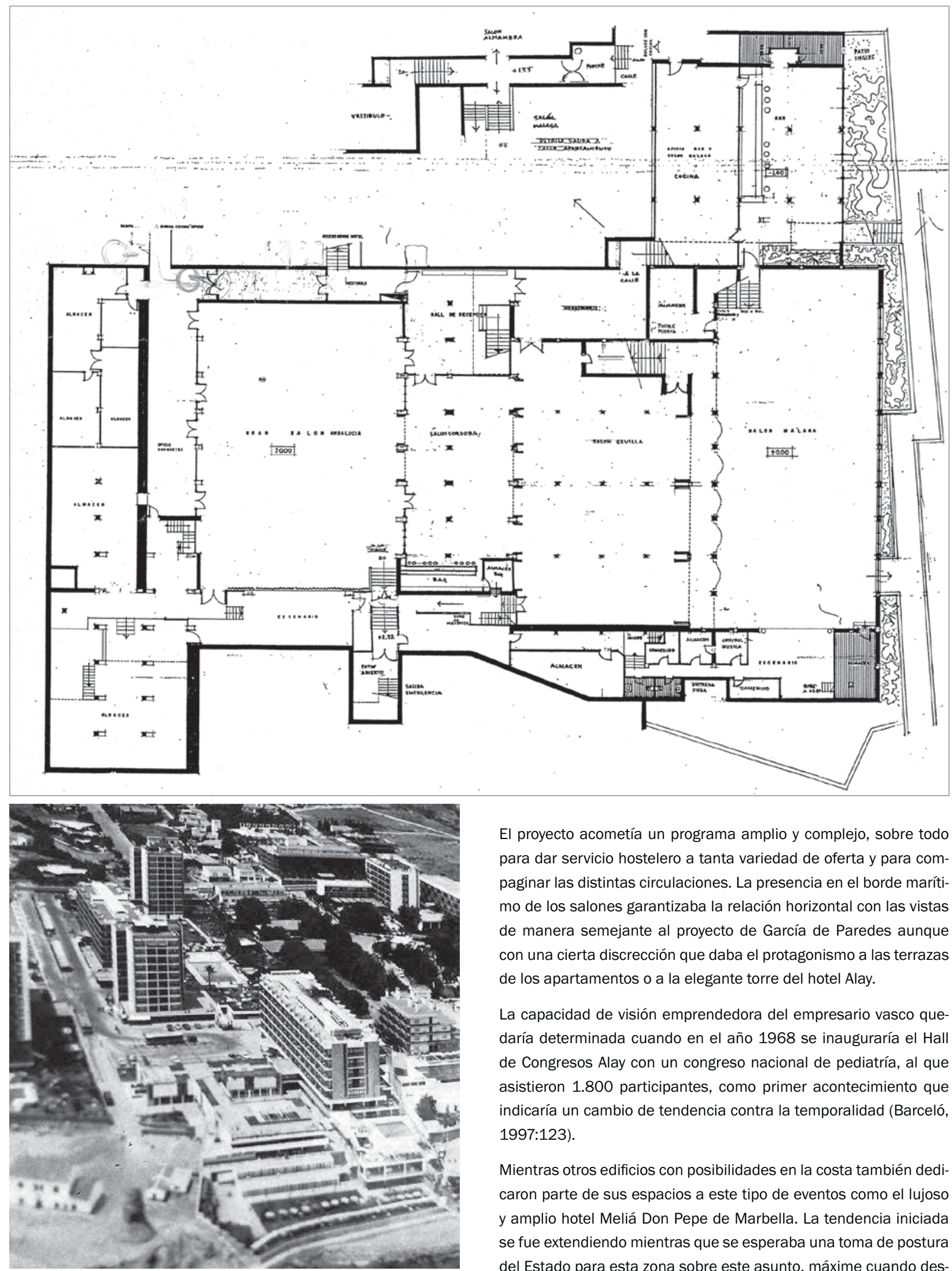

El proyecto acometía un programa amplio y complejo, sobre todo para dar servicio hostelero a tanta variedad de oferta y para compaginar las distintas circulaciones. La presencia en el borde marítimo de los salones garantizaba la relación horizontal con las vistas de manera semejante al proyecto de García de Paredes aunque con una cierta discrección que daba el protagonismo a las terrazas de los apartamentos o a la elegante torre del hotel Alay.

La capacidad de visión emprendedora del empresario vasco quedaría determinada cuando en el año 1968 se inauguraría el Hall de Congresos Alay con un congreso nacional de pediatría, al que asistieron 1.800 participantes, como primer acontecimiento que indicaría un cambio de tendencia contra la temporalidad (Barceló, 1997:123).

Mientras otros edificios con posibilidades en la costa también dedicaron parte de sus espacios a este tipo de eventos como el lujoso y amplio hotel Meliá Don Pepe de Marbella. La tendencia iniciada se fue extendiendo mientras que se esperaba una toma de postura del Estado para esta zona sobre este asunto, máxime cuando desde principios de los años 60, únicamente Barcelona contaba con un palacio de congresos en el panorama nacional español. 


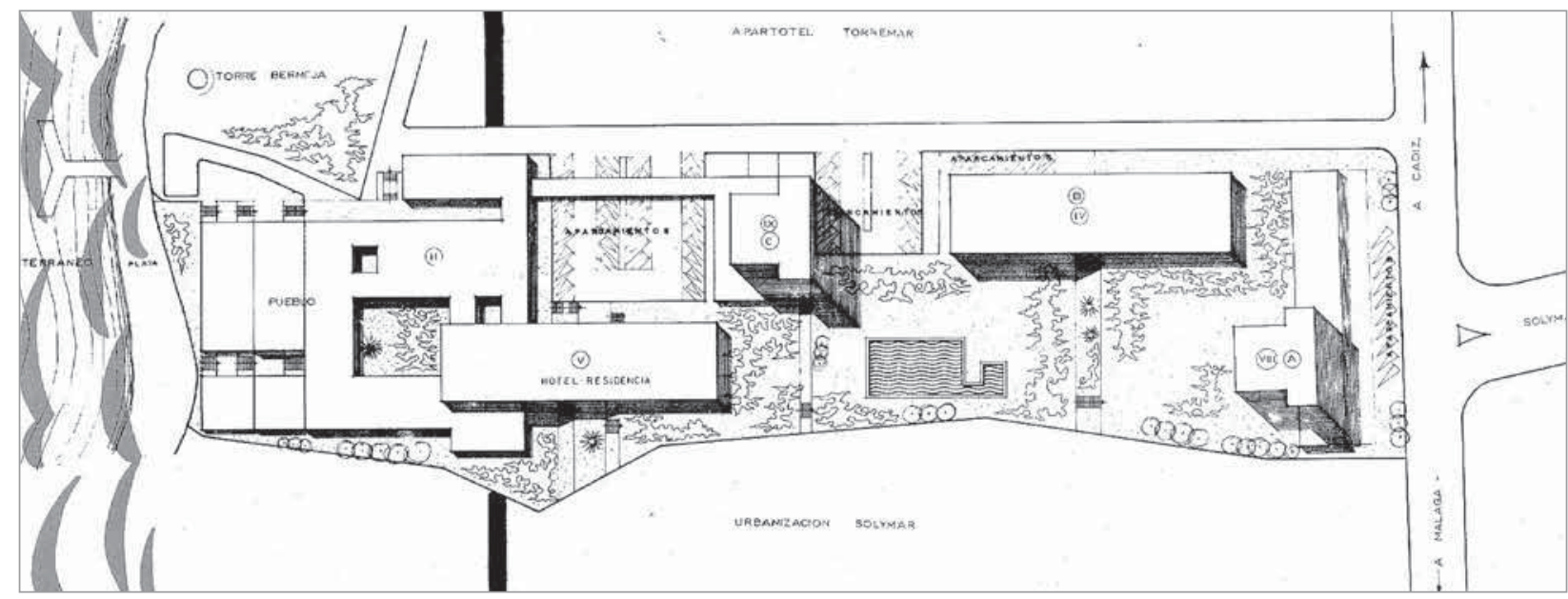

\section{LA CONSTATACIÓN DEL HECHO: EL PALACIO DE CONGRESOS DE TORREMOLINOS (1967-1969)}

Como ya se ha visto, la primera propuesta de palacio de convenciones no prosperó aunque ya era indicativo de cuáles eran las condiciones de partida que se buscaban: Un edificio representativo y suficiente para albergar las diferentes sesiones de congresos, en un lugar elevado sobre alguna colina próxima al mar y al aeropuerto internacional, de ahí su ubicación en Torremolinos, y a ser posible encargado a un arquitecto de prestigio, como ya lo eran en la época García de Paredes o Rafael de La-Hoz.

Entre tanto las iniciativas privadas, como las del Alay, el hotel Meliá Don Pepe y otras, continuarían insistiendo desde los hechos sobre la necesidad de introducir esta nueva actividad que complementase la zona como destino de intercambio, no sólo de sol y playa, sino también de conocimiento.

Sin embargo pese al apoyo inicial la administración del Estado, personalizada en el Ministro de Información y Turismo, Manuel Fraga, se continuaba sin consignar presupuesto para este fin.

La Cooperativa de Promotores había hecho suyo el empeño sobre esta labor desde que en 1965 acordó como uno de sus principales objetivos llegar a conseguir un palacio de congresos (Barceló, 1997:123).

En vista de la inacción gubernamental la Cooperativa de Promotores decidió pasar a los hechos. En primer lugar fueron comprados $72.000 \mathrm{~m}^{2}$ en unos terrenos ubicados en un olivar en la parte alta de Torremolinos (Diario Sur, 26.02.1967).

A la vez les fue encargado el proyecto definitivo en esta ocasión a Rafael de La-Hoz y a Gerardo Olivares, que ya habían participado en el primer proyecto (1965) junto a José María García de Paredes.

Las condiciones de partida del proyecto eran semejantes a las de la propuesta de La Batería, y aunque su colocación rozaba la falda de la Sierra de Mijas y por tanto se encontraba algo más retirada de la costa, su posición más elevada garantizaba las vistas de la bahía. Por otro lado y como veremos a continuación el proyecto define un programa preciso y complejo y en cuanto a concepto y forma también distaría bastante de las cubiertas horizontales sobre terrazas transparentes del primero.

Los dos arquitectos cordobeses no escatimaron en esfuerzos a la hora de plantear el programa que se dividiría en dos edificios, uno para alojar congresos y el otro para exposiciones. Aunque fi-

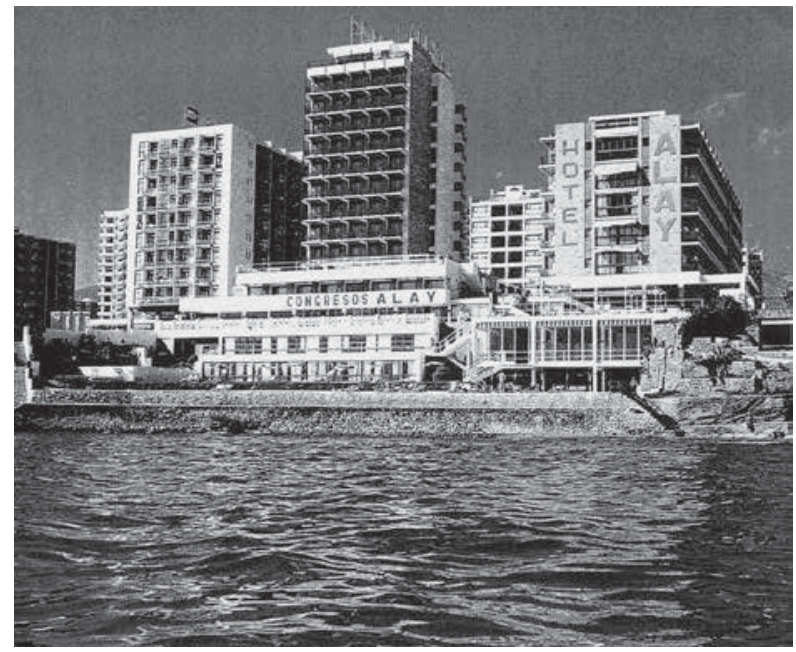

Figura 9. Frontal al mar de los salones de congresos Alay. Fuente: estudio del arquitecto Manuel Hugo Jaén de Zulueta. 

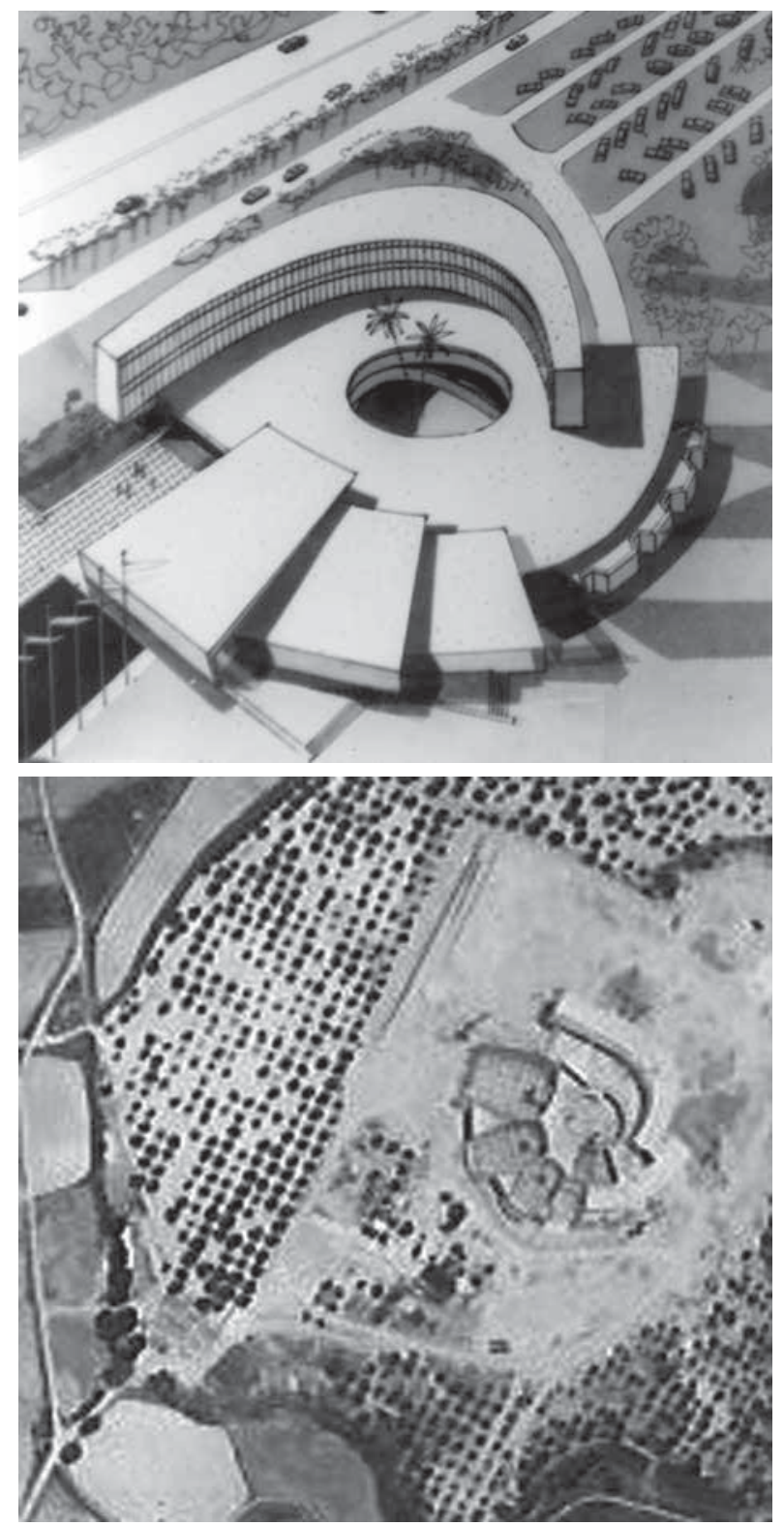

Figura 10. Boceto inicial del Palacio de Congresos de Torremolinos. Fuente: estudio del arquitecto Rafael de La-Hoz Castanys.

Figura 11. Primera huella del Palacio de Congresos de Torremolinos debida al movimiento de tierra. Fuente: estudio del arquitecto Luis Alfonso Pagán. nalmente solo se construiría el primero de ellos. Para poder definir este novedoso programa para casi dos mil congresistas para el que recurrieron básicamente a dos herramientas, según consta en la memoria que acompaña a la publicación del proyecto en la revista Arquitectura en el año 1971, por un lado las recomendaciones de la UNESCO y por otro las del $4^{\text {th }}$ International Congress on Organization, celebrado en Copenhague en 1966 (De La-Hoz \& Olivares, 1971:9, 12).

Las condiciones del terreno en el que el edificio se asentaría aportarían el detonante organizativo al que se adaptaría la forma del edificio:

\begin{abstract}
La topografía del emplazamiento permite situar las zonas de delegados y público en dos plantas superpuestas con acceso directo ambas, desde el exterior.
\end{abstract}

Abrazando dichas zonas se dispone la gama completa de locales de asamblea, todos en conexión con la planta de delegados y los tres mayores, de carácter público, enlazados con el mismo.

La zona de oficinas se compone de un bloque diferenciado que abraza, cerrando el perímetro y los vestíbulos público y privado...

A fin de iluminar el espacio incluido entre los contornos de locales de asamblea y oficinas, se crea un gran patio circular con techo traslúcido en una atmósfera de recogimiento, que sólo se enlaza con el exterior en la zona de público mediante el espacio de exposiciones.

Bordean dicho vestíbulo escalinatas para permitir, opcionalmente, los contactos personales entre los ambientes de público y delegados (De La-Hoz \& Olivares, 1971:10-12).

Por lo tanto, en primer lugar la topografía del terreno adquiere gran trascendencia en el funcionamiento interno del edificio al permitir que sucedan dos entradas diferentes con distintas orientaciones y niveles de acceso.

La planta inferior, que fue denominada como Planta de Delegados, de carácter más privado y organizativo, y por tanto se configura más cerrada e íntima al no permitir vistas del exterior. La aproximación a esta entrada desde el exterior es más inmediata y surge semioculta en el nivel inferior no queriendo destacar e incluso no mostrando el espacio interior de manera directa mediante una especie de recodo.

La planta superior, denominada Planta de Público, sería la de acceso general al edificio, más diáfana y expansiva, en la que se divisa el paisaje costero desde un interior más luminoso a través de un mirador a modo de visera horizontal, orientado al levante, que culminaría en la zona opuesta al acceso y destinada a exposiciones. En este caso la aproximación al exterior es más ceremoniosa al facilitar la promenade mediante una explanada. Estanque y jardines reciben al visitante desde un plano horizontal que culmina el recorrido curvo de llegada y exhibe desde su plataforma el paisaje que viste la estancia. Se podría decir que el recorrido de acercamiento nace en un lugar externo a la propia parcela iniciando un enroscamiento que altera la condición espacio temporal y reubica en el sitio adecuado al visitante desde un ritual dinámico.

El segundo punto importante que la propuesta no quiere dejar sin definir es aquel que considera al edificio como punto de encuentro. Un congreso no deja de ser un acto social de intercambio de cono- 


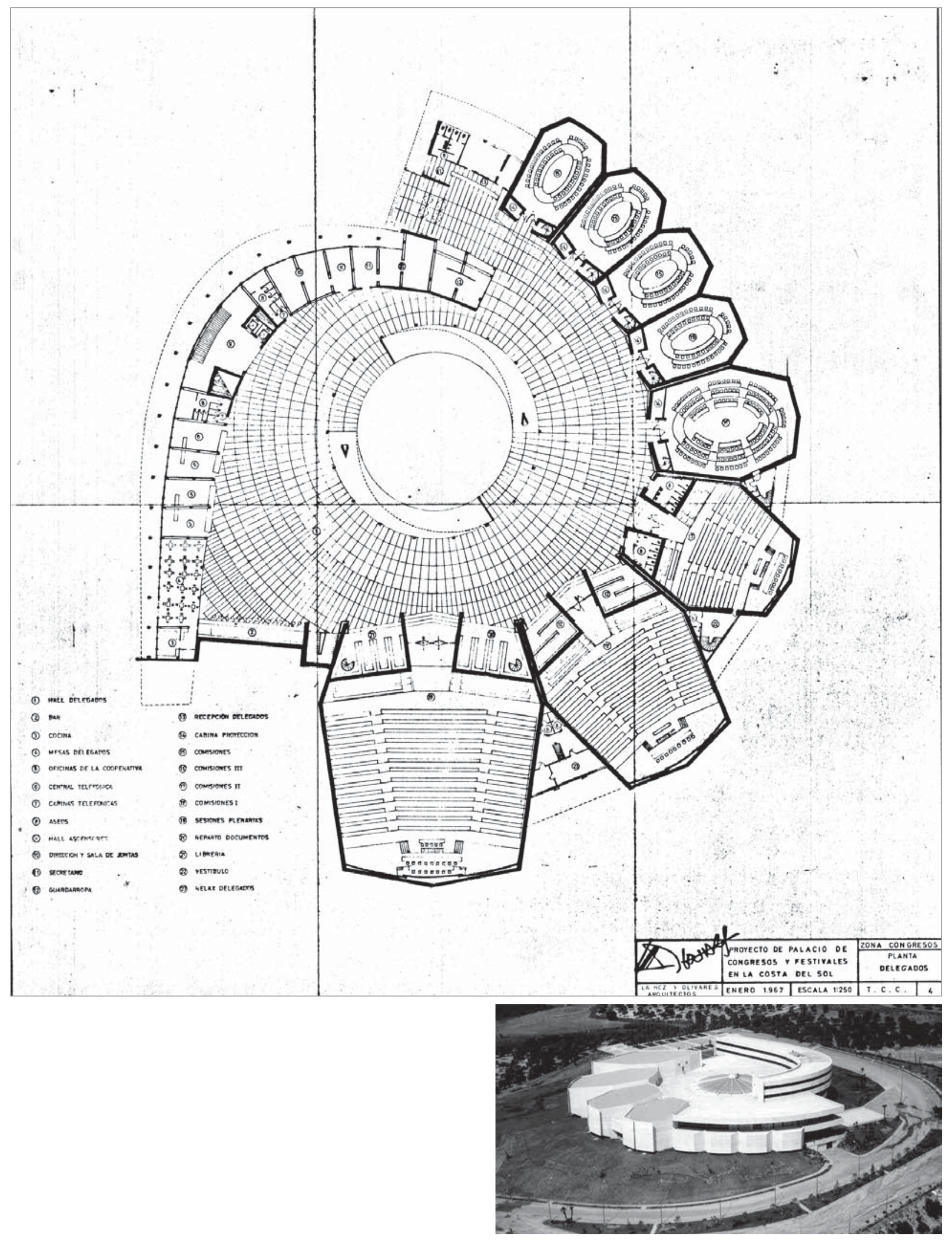

Figuras 12 y 13. Planta de Delegados, nivel inferior, de uso más restringido y ambiente más recogido. Fuente: estudio del arquitecto Rafael de La-Hoz Castanys. 

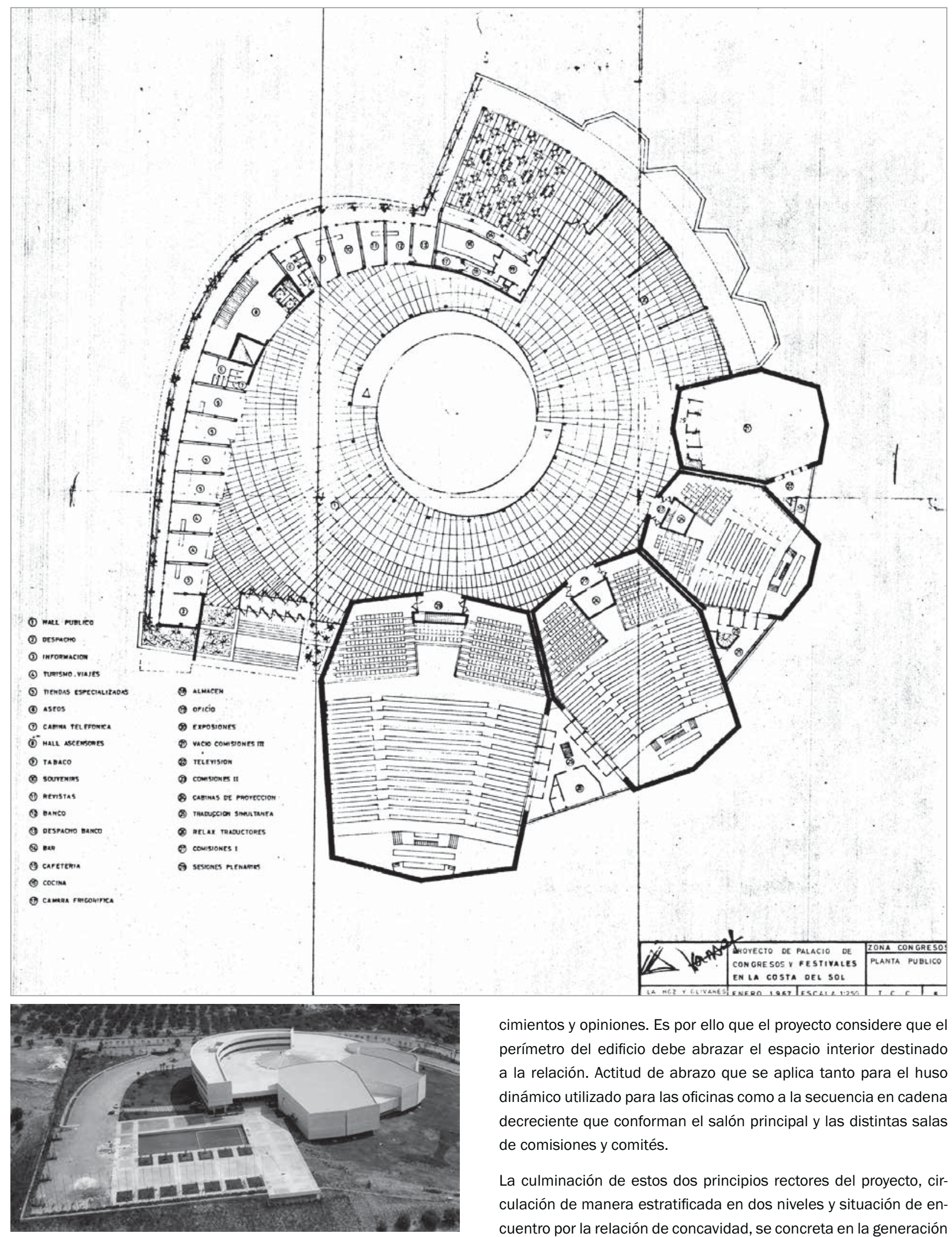

cimientos y opiniones. Es por ello que el proyecto considere que el perímetro del edificio debe abrazar el espacio interior destinado a la relación. Actitud de abrazo que se aplica tanto para el huso dinámico utilizado para las oficinas como a la secuencia en cadena decreciente que conforman el salón principal y las distintas salas de comisiones y comités.

La culminación de estos dos principios rectores del proyecto, circulación de manera estratificada en dos niveles y situación de encuentro por la relación de concavidad, se concreta en la generación de un gran vacío. Se trata de un espacio que focaliza los encuentros y genera una capacidad de sorpresa que compite en sensaciones con el paisaje exterior que se introduce desde su mirador. Toda la construcción del edificio parece encaminada hacia este punto de encuentro sin solución de continuidad. Del centro del espacio surge suspendida una lámpara de luz natural filtrada que se vierte amablemente en una mezcla de ingravidez y seducción. El edificio muestra con esta continuidad muchas caras en su exterior, para establecer el ingreso en el punto final del recorrido.

ciones abierta a las vistas. Fuente: estudio del arquitecto Rafael de La-Hoz Castanys. 

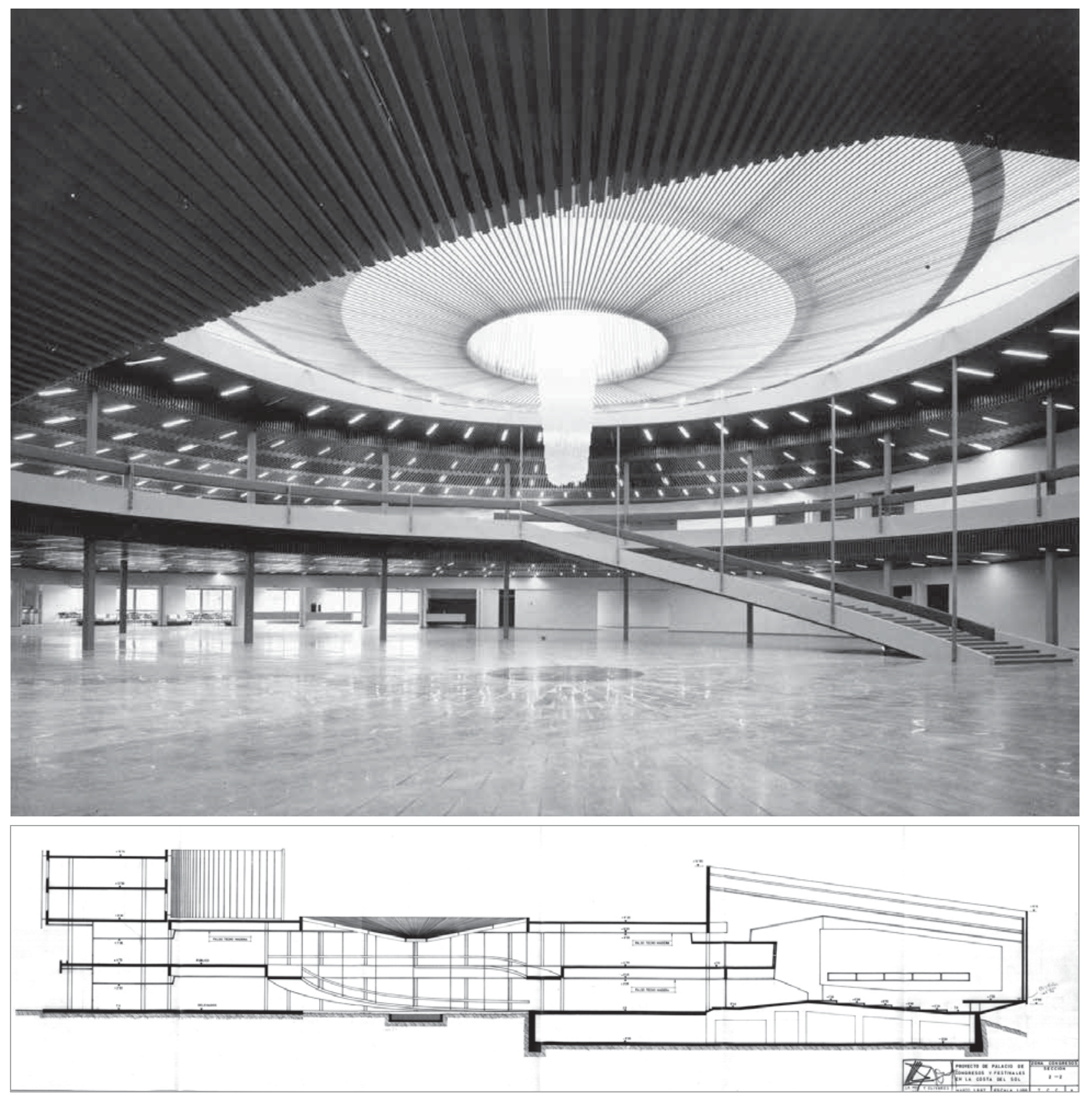

Las dos suaves escalinatas del perímetro circular interior plantean sin sobresaltos una nueva condición de interacción entre lo público y lo privado en un lugar de encuentros mucho más ambiguo y transgresor.

El sumatorio de intenciones diversas que confluyen en el edificio genera una tensión entre lo liviano de su interior, enfatizado por los finos soportes en el vacío iluminado, y la suma de convexidades pétreas del exterior:

La organización del edificio hace expresa exteriormente la gama completa de locales de asamblea en una espiral decreciente de volúmenes ciegos que se equilibran con la apertura del salón de exposiciones.

La forma cóncava del sólido superior del cuerpo de oficinas, muy abierto, procura cierto contraste con el volumen cerrado anterior creando un espacio acogedor (De La-Hoz \& Olivares, 1971:12).

$>$ Figura 16. Linterna tamizada que corona el patio circular. Fuente: estudio del arquitecto Rafael de La-Hoz Castanys.

$>$ Figura 17. Sección longitudinal por las oficinas el patio cubierto y la sala de comisiones para 248 plazas. Fuente: estudio del arquitecto Rafael de La-Hoz Castanys. 

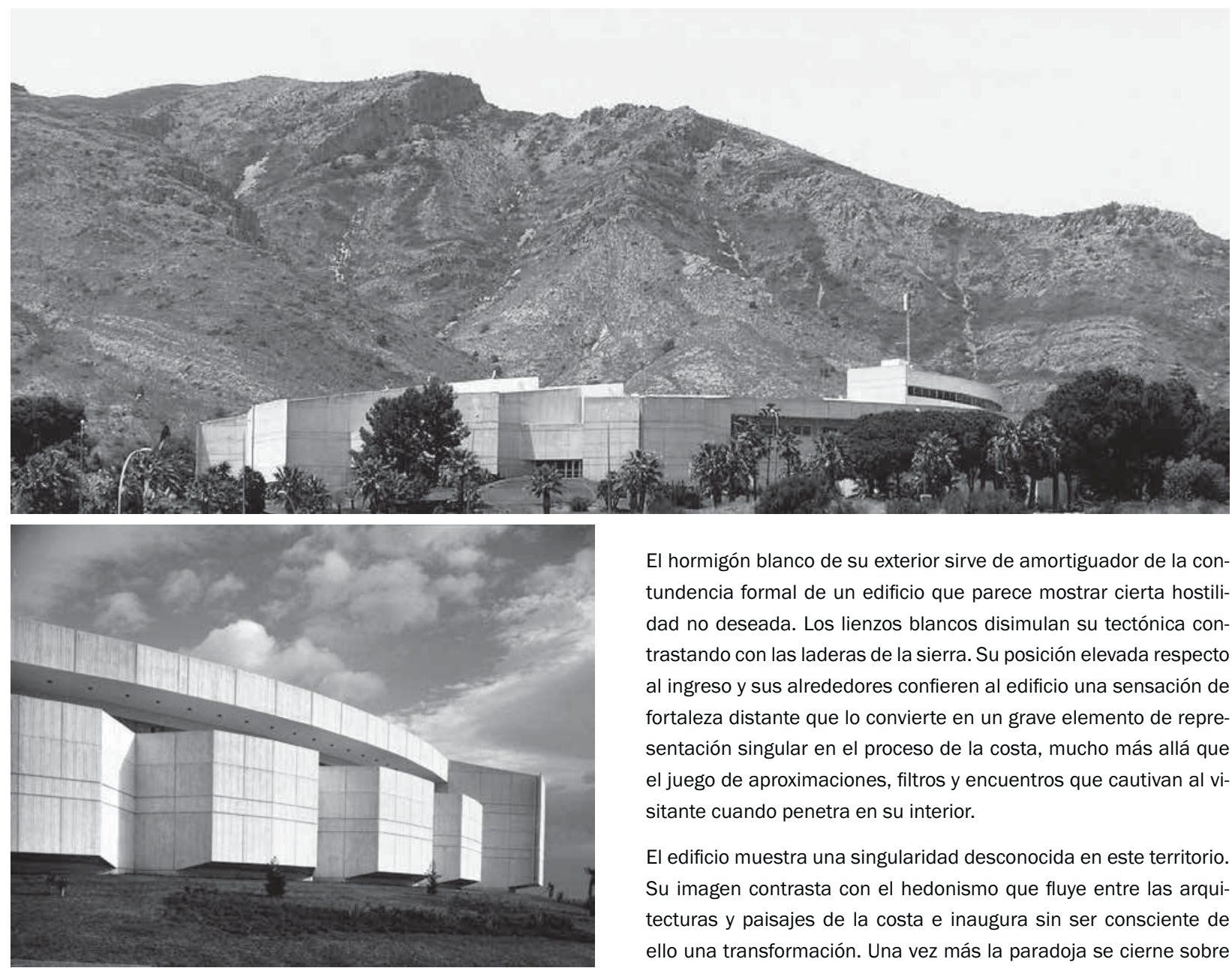

El hormigón blanco de su exterior sirve de amortiguador de la contundencia formal de un edificio que parece mostrar cierta hostilidad no deseada. Los lienzos blancos disimulan su tectónica contrastando con las laderas de la sierra. Su posición elevada respecto al ingreso y sus alrededores confieren al edificio una sensación de fortaleza distante que lo convierte en un grave elemento de representación singular en el proceso de la costa, mucho más allá que el juego de aproximaciones, filtros y encuentros que cautivan al visitante cuando penetra en su interior.

El edificio muestra una singularidad desconocida en este territorio. Su imagen contrasta con el hedonismo que fluye entre las arquitecturas y paisajes de la costa e inaugura sin ser consciente de ello una transformación. Una vez más la paradoja se cierne sobre este territorio. Este edificio había sido reclamado insistentemente por una sociedad privada de promotores y empresarios para que la administración lo convirtiese en el equipamiento de referencia en la costa. Sin embargo, contra todo pronóstico la Cooperativa de Promotores financió con un crédito del Banco Coca el edificio en su totalidad mientras que el estado inauguraba los de titularidad pública de Madrid y Palma. El Palacio de Congresos se inauguró en mayo de 1970 con el Congreso Internacional EUCEPA (Unión Europea de Celulosas y Papel), al que asistieron mil participantes, bajo la gestión de la Cooperativa de Promotores.

En el año 1971 Patrimonio Nacional del Estado español compraría el palacio y los terrenos por trescientos millones según la valoración presupuestaria del terreno empleado en adquirir los terrenos y la construcción del edificio. El Ministerio de Información y Turismo sería a partir de ese momento el encargado de su gestión (Barceló, 1997:124).

El edificio del Palacio de Congresos de Torremolinos no deja de ser un edificio singular en el fenómeno de la costa por diversos motivos. Su contundencia formal choca con la cultura de la imagen nacida en los 60 que empieza a extenderse por las ciudades y mucho más en el territorio turístico. El aspecto de fortaleza, justificado por la seriación de espacios interiores de reuniones, se presta a otras interpretaciones que certifican lo que está ocurriendo.

Figura 18. El Palacio de Congresos de Torremolinos sobre su colina. Autor: Juan Gavilanes, 2009.

Figura 19. Mirador protegido para el público a través de la zona de exposición y sobre las salas menores. Autor: Juan Gavilanes, 2007. 
relaciones económicas manifiesta un larvado proceso de colonización que da comienzo entonces. El desembarco inicial del turismo produjo un extrañamiento inocente de contraprestaciones compartidas en una deriva de la que sólo fueron conscientes algunos técnicos y que la sociedad no negó porque multiplicaba las oportunidades de trabajo y abrió las puertas a otras culturas.

El Palacio de Congresos nació con el objetivo de complementar y ampliar el tiempo de explotación de la Costa del Sol y al empezar a usarse todo el año empezó a poder ser habitada de manera estable.

La posibilidad de estabilización temporal suponía también la culminación del proceso de colonización. Este palacio pétreo y cerrado también funcionó como un baluarte feudal que visualiza el poder de un Estado que no quiso o no pudo estar y que finalmente fue casi obligado a ello. Solà-Morales (2009) aporta de nuevo un punto de acuerdo, que parece adecuado, en este sentido en su artículo Anyway:

El poder del Estado o del conocimiento se des-pliega en una microfísica que acaba materializándose en estructuras sólidas, en no pocos casos arquitectónicos.

Sin embargo, ha sido Gilles Deleuze quien ha señalado agudamente que, en Foucault, la descripción de los dispositivos del poder se hace a partir de formas cerradas. El poder, para Foucault, encierra con el fin de controlar, y este control no parece que pueda ejercerse de mejor manera que a través de estructuras físicas capaces de aislar. La conexión entre control y aislamiento físico parece ser una relación dominante en Foucault. Cualquiera de las formas de materialización y visualización del poder se hace a través de construcciones que habitualmente son arquitecturas cerradas...

Del dominio militar colonial se pasa al dominio económico y financiero, de modo que las máquinas de poder ya no tienen por qué ser estructuras físicas opacas, sino que pueden desplegarse a través de la transparencia y la desmaterialización (Solà-Morales, 2009:52-53).

Los dos extremos se encuentran en el palacio, las formas cerradas de su interior albergan en su vientre un espacio de transparencia y desmaterialización donde se inicien nuevas relaciones e intercambios más continuos y duraderos incrementados con la evolución inmaterial de las telecomunicaciones.

El palacio quedaría como el primero de una hipotética red simbólica de hitos o monumentos a través de la Costa del Sol que no llegaría a culminarse nunca de esta manera. El palacio surgiría como entidad material justo en el momento en el que los códigos de apropiación, relación e intercambio se tornarían cada vez más virtuales. Aun así este palacio certificaría con su presencia que una ciudad estaba apareciendo aunque los sistemas de signos empezasen a cambiar de manera simultánea. El propio edificio como entidad y por supuesto como arquitectura sería incapaz de trasmitir ningún modo de comportamiento máxime cuando el cambio devenía de la actividad de su exterior (García, 2004:182).

En cierta manera esta circunstancia es compartida con la mayoría de las arquitecturas provenientes del turismo durante esos años en la Costa del Sol, de las que el Palacio de Congresos se distingue por su función pública. Todas estas arquitecturas del turismo, con un fuerte carácter exótico, que aparecían como cápsulas atractoras de hedonismo, irían paulatinamente despojándose de cualquier capacidad simbólica, que fue ofrecida mayoritariamente como reclamo comercial. A medida que una nueva ciudad en aparición fue creciendo se tornaría en maleza que los fue ocultando lentamente, desposeyéndolos de su misión inicial de reclamo de una sociedad modernizada y relegándolos a la condición casual de meros supervivientes entre sus nuevas calles.

\section{BIBLIOGRAFÍA}

BANHAM, R. (1960), "Theory and Design in the First Machine Age”, Londres: Architectural Press; Nueva York: Praeger. Primera edición en español: Buenos Aires, 1965. Segunda edición en español en Barcelona y Buenos Aires: Paidós, 1985.

BANHAM, R. (1971), "Los Angeles: The Architecture of Four Ecologies", London: Allen Lane. Reeditada en 2001, Berkeley y Los Ángeles, California: University of California Press.

BARCELÓ, S. (1997), Las primeras promociones organizadas. La promoción turística institucionalizada a través de la Cooperativa de Promotores de la Costa del Sol, "Historia de la Costa del Sol”, AA.VV., Málaga: Ed. Prensa Malagueña S.A., Diario Sur, pp. 115-116.

BASES DEL CONCURSO INTERNACIONAL DE IDEAS PARA LA ORDENACIÓN DE LA ZONA RESIDENCIAL ELVIRIA (1960), Madrid: Consejo Superior de Arquitectos de España. Colegio Oficial de Arquitectos de Madrid, Unión Internacional de Arquitectos (UIA), Dirección General de Urbanismo, Salvador Guerrero, promotor, 1960. Al arquitecto malagueño Francisco González Fernández se las debo.

DE LA-HOZ, R. y OLIVARES, G. (1971), Palacio de Congresos de Torremolinos, revista Arquitectura No 150, Madrid: Revista del Colegio de Arquitectos de Madrid, pp. 9-12.

DELEUZE G. y GUATTARI F. (1977), "Rhizome (Introduction)", París: Éditions de Minuit. Traducción al castellano: "Rizoma, introducción”, Valencia: Pre-Textos, 2005, pp. 20, 43, 47.

DIARIO SUR DE MÁLAGA (1967), edición del 26 de febrero de 1967.

FLORES, C. (1965), La arquitectura de García de Paredes, Revista Hogar y Arquitectura, $N^{\circ} 61$, nov-dic 1965, pp. 18-19.

FRAMPTON, K. (1980), "Modern Architecture: A Critical History", Londres: Thames and Hudson Ltd., Barcelona: Gustavo Gili, 2005. Citando el libro "The Disappearing City" (1932) de F. L. Wright, pp. 192

GARCÍA DE PAREDES, J. M.; DE LA-HOZ, R. y OLIVARES, G. (1965), Centro de Convenciones y Congresos. Torremolinos, revista Hogar y Arquitectura, N 61, nov-dic 1965, pp. 62-64.

GARCÍA VÁZQUEZ, C. (2004), "Ciudad hojaldre”, Barcelona: Editorial Gustavo Gili, p. 182

LYNCH, K. (1960), "The image of the city". Cambridge, Massachusetts: Institute of Technology Press. Edición castellana, Barcelona: Editorial Gustavo Gili, SL, Barcelona, 1984, 1998.

MAFFESOLI, M. (1996), "Éloge de la raison sensible". Traducido al español como "Elogio de la razón sensible. Una visión intuitiva del mundo contemporáneo", Barcelona: Ediciones Paidós Ibérica S.A., 1997, pp. 24-25. 
SARTRE, J.-P. (1945), Villes d'Amérique, publicado originalmente como una serie de artículos en el periódico Le Figaro los días 6, 13, 14 y 23 de abril de 1945. También en el recopilatorio de textos: Sartre J.-P. (1949). En "Situations III", París: Librairie Gallimard, 1949. También apareció traducido al inglés como American cities en: Sartre J.-P. (1955) "Literary and Philosophical Essays". Traducido del francés al inglés por Michelson Annette. New York: Criterion Books, INC, 1955, pp. 116-121.

SOLÀ-MORALES, I. (2009), Anyway. En "Los artículos de Any", Barcelona: Fundación Caja de Arquitectos, pp. 52, 53.

UTZON, J. (1962), Platforms and Plateaus: Ideas of a Danish Architect, Revista Zodiac, Nº 10, Milán: Edizioni di Comunità, 1962, pp. 120, 124.

\section{NOTAS}

1 ...Los Ángeles, en particular, es más bien como una enorme lombriz que pudiese ser cortada en veinte piezas sin ser asesinada. Cuando te desplazas a través de este enorme racimo urbano, probablemente el más grande del mundo, te encuentras con veinte ciudades yuxtapuestas, estrictamente idénticas, cada una con un suburbio pobre, con sus calles comerciales, sus clubes nocturnos y su zona elegante, uno tiene la impresión de que un centro urbano de tamaño medio se ha reproducido veinte veces...En los Estados Unidos... las ciudades...que evolucionan a gran velocidad, no se construyen con el fin de llegar a viejas, si no que se mueven hacia adelante como los ejércitos modernos, rodeando aquellas islas de resistencia que no son capaces de destruir, el pasado no se manifiesta en ellos como lo hace en Europa, a través de los monumentos públicos, sino a través de supervivencias. ( $\mathrm{N}$ del $\mathrm{T}$ ). 